\title{
Article \\ Depression, Anxiety and Stress on Caregivers of Persons with
Dementia (CGPWD) in Hong Kong amid COVID-19 Pandemic
}

\author{
Tommy Kwan-Hin Fong ${ }^{1}$, Teris Cheung ${ }^{2}\left(\mathbb{D}\right.$, Wai-Chi Chan ${ }^{1}$ and Calvin Pak-Wing Cheng ${ }^{1, *(D)}$ \\ 1 Department of Psychiatry, The University of Hong Kong, Hong Kong, China; tommykhf@hku.hk (T.K.-H.F.); \\ waicchan@hku.hk (W.-C.C.) \\ 2 School of Nursing, The Hong Kong Polytechnic University, Hong Kong, China; teris.cheung@polyu.edu.hk \\ * Correspondence: chengpsy@hku.hk
}

check for

updates

Citation: Fong, T.K.-H.; Cheung, T.;

Chan, W.-C.; Cheng, C.P.-W.

Depression, Anxiety and Stress on

Caregivers of Persons with Dementia (CGPWD) in Hong Kong amid

COVID-19 Pandemic. Int. J. Environ.

Res. Public Health 2022, 19, 184.

https://doi.org/10.3390/

ijerph19010184

Academic Editor: Paul B. Tchounwou

Received: 22 November 2021

Accepted: 23 December 2021

Published: 24 December 2021

Publisher's Note: MDPI stays neutral with regard to jurisdictional claims in published maps and institutional affiliations.

Copyright: (c) 2021 by the authors. Licensee MDPI, Basel, Switzerland. This article is an open access article distributed under the terms and conditions of the Creative Commons Attribution (CC BY) license (https:// creativecommons.org/licenses/by/ $4.0 /)$.

\begin{abstract}
Background: Coronavirus disease 2019 (COVID-19) contributed to increasing prevalence of depressive symptoms and other psychological repercussions, particularly in the disease population in Hong Kong. Nonetheless, the caregiver burden of caregivers of persons with dementia (CGPWD), has been under-investigated. Aims: This study examined the psychological impact and its correlates on the CGPWD in Hong Kong amid the COVID-19 outbreak. Methods: CGPWD referred from rehabilitation clinics and online seminar were used to recruit participants to complete an online questionnaire by the end of the second-wave of the COVID-19 outbreak (June 2021). To be eligible, either full-time or part-time CGPWD, aged 18 or above, can understand Cantonese, currently reside in Hong Kong and offering care to PWD for at least one year, were recruited. Those CGPWD diagnosed with any type of psychiatric disorder were excluded from this study. The Chinese Center for Epidemiologic Studies Depression Scale (CES-D), Perceived Stress Scale (PSS-10), Generalized Anxiety Disorder (GAD-7), Zarit Burden Interview (ZBI-22), and Nonattachment Scale (NAS-7) were used to measure participants' depression, perceived stress, anxiety symptoms, caregiver burden and wisdom in subjective feelings of internal stress. The modified Medical Outcomes Study Social Support Survey (mMOS-SS) and the SARS Appraisal Inventory (SAI) were also administered to measure participants' perceived support and coping efficacy. Follow-up responses were gathered by the end of third-wave outbreak (October 2021). Results: A total of 51 CGPWD participated, of which, 33 (64.7\%) suffered from probable depression (CES-D score $\geq 16$ ). Participants also showed a significant increase in depression symptom scores at the three-month follow-up period $(\mathrm{t}=2.25, p=0.03)$. CGPWD with probable depression had less non-attachment awareness and higher scores in anxiety, stress, caregiving burden, and coronavirus impact (all $p<0.05)$ than those without. Conclusions: High prevalence of depressive symptoms was noted among our CGPWD sample and these symptoms seemed to worsen substantially. Contingent online mental health support should be prioritized to those CGPWD to reduce psychiatric morbidity and the global disease burden.
\end{abstract}

Keywords: COVID-19; CGPWD; mental health; depression; anxiety; stress

\section{Introduction}

The coronavirus disease 2019 (COVID-19) has been rapidly transmitted to more than 220 countries nationwide. Hong Kong is no exception. As of 18 December 2021, Hong Kong has had 12,513 total COVID-19 cases, with 213 deaths [1]. Comparing the total number of COVID-19 cases of more than 27 million nationwide with 5.33 million deaths, the situation in Hong Kong represents but the tip of the iceberg [2].

The rapid transmission of this novel virus has inevitably created an apprehensive atmosphere, widespread anxiety and uncertainty to the general public [3]. Citizens are confronted with this highly contagious novel virus which may bring about irreversible damage, jeopardizing both physical and mental health [4]. The enforcement of stringent infection control measures in affected countries/regions including compulsory face mask wearing, social distancing, quarantines, lockdowns, and closure of entertainment facilities 
and sports amenities may lead to social withdrawal, anxiety and fear, boredom, loneliness, anger [3] and depression [5].

Notwithstanding the socio-economic burden brought by the COVID-19 pandemic, it also adds enormous physical and psychological burden on existing healthcare systems, particularly on health professionals, infected patients, suspected cases and their family caregivers [6]. The general population is also affected, especially during the lockdown periods; non-emergency community or day service centres were temporarily suspended in Hong Kong. Suspension of existing services will add more strain on caregivers during the pandemic. Prolonged physical exhaustion may jeopardize family caregivers' mental well-being. Emerging local evidence from a recent cross-sectional survey [7] found that the anxiety levels of Hong Kong citizens are hitting record highs, with $88 \%$ of respondents $(\mathrm{N}=1168)$ reporting borderline abnormal anxiety $(88 \%)$ when they have possible contact with COVID-19 cases. Another large-scale cross-sectional study which surveyed 11,072 Hong Kong adults from March 2020 to April 2020 discovered a high point-prevalence of probable depression and suicidal traits during the COVID-19 outbreak, and those wearing face masks for self-protection were more prone to depression [8]. Most COVID-19 infections are not severe [9]. In fact, the majority of the fatal cases usually occurred in elderly patients with underlying medical comorbidities [10]. Thus, it is understandable that older adults may have more fear of infection as they have higher risks of susceptibility to COVID-19 and a higher chance of it developing into severe medical condition [11]. In fact, one of the most prevailing health conditions associated with aging is dementia. Conceivably, the outbreak of COVID-19 will afflict persons with dementia and their caregivers by restricting daily living as well as aggravating their psychological concerns.

Notably, a significant proportion of older adults in Hong Kong are suffering from dementia. It is estimated that every 5 to 8 adults aged 65 or above, suffer from dementia in every 100 older adults, and the ratio will spiral up to every 1 in 5 per 100 older adults if they aged over 80 years old [12]. More importantly, caregivers of persons with dementia (CGPWD) are predominantly middle aged or older age adults themselves. Thus, it is unsurprising that CGPWD are more vulnerable to depression or anxiety [13]. The higher the dependency level of the dementia patient in activities of daily living and the more severe and frequent behavioural symptoms, the more likely the CGPWD will develop depressive symptoms [14]. Caregiving accounted for high levels of stress among CGPWD in Hong Kong [15]. There is ample empirical evidence supporting the negative detrimental impact of the caregiving burden; however, the psychological impact on those CGPWD in Hong Kong during the COVID-19 pandemic has not been thoroughly investigated.

Despite some evidence demonstrating the negative detrimental impact of COVID19 on the caregiving burden, research evidence is insufficient to influence policymaking. For instance, an online cross-sectional study in Italy involving 84 CGPWD discovered higher caregiving burden, depression and anxiety levels during the COVID-19 lockdown period [16]. Another web survey conducted in Japan on 635 CGPWD investigating their quality of life, caregiving burden and work productivity. Results showed that $50.5 \%$ of the primary caregivers had significantly lower quality of life and higher work impairment than non-primary caregivers [17] while another local qualitative study shared similar findings regarding caregiving burden on stroke caregivers [18]. Nonetheless, there is by far no local study investigating the impact of COVID-19 in the long-term caregiving on CGPWD in Hong Kong.

Since late March 2020, quarantine measures and social distancing have been imposed by the Hong Kong government, such as restrictions on social gatherings and temporarily closure of recreational facilities and sports amenities [19]; these stringent measures are still in force at the time of reporting. With prolonged caregiving duration, CGPWD caregivers would have limited time for relaxation, and accumulated stress and anxiety may trigger depressive symptoms if they go untreated in a timely fashion. A high level of caregiving burden would also contribute to caregivers' poor self-rated health, adverse health behaviours, and increased visits to healthcare services [20]. Such claims have been supported 
by a nationwide survey involving 4913 dementia caregivers in Italy, with more than half of respondents showing exacerbated behavioural and psychological symptoms after one month of quarantine [21]. Conceivably, we could postulate that the prolonged COVID-19 situation aggravated depressive symptoms of CGPWD [8]. Therefore, it is imminent to examine the psychological impacts of COVID-19 on CGPWD and investigate the conceivable elements that may help planning early mental health prevention and intervention amid the COVID-19 pandemic in Hong Kong. The aim of this study was three-fold: first, to determine whether the mental health of CGPWD in Hong Kong was adversely influenced by the second-wave of the COVID-19 outbreak (March 2020 to May 2020); second, to examine the psychological status of these CGPWD by the end of the third-wave of the COVID-19 outbreak (July 2020 to September 2020); and third, to identify the prevalence and correlates of outcome variables (i.e., depression, perceived stress, anxiety, perceived social support, coping efficacy) among the CGPWD.

\section{Methods}

\subsection{Study Design}

This was a cross-sectional study using convenience sampling method. Participants were instructed to complete a baseline questionnaire in traditional Chinese, the official written language in Hong Kong. Follow-up responses were collected by the end of the third-wave of the COVID-19 outbreak (July 2020 to September 2020).

\subsection{Subjects}

To be eligible, participants should be: (1) able to read/understand Cantonese (official spoken language in Hong Kong) and currently reside in Hong Kong; (2)aged 18 or above; (3) full-time or part-time informal caregivers (e.g., unpaid family members) who offer care towards the PWD for one year or more. CGPWD diagnosed with any types of psychiatric illnesses or currently receiving psychotherapy were excluded from this study.

\subsection{Ethical Considerations}

This study was approved by the Institutional Review Board of The University of Hong Kong/Hospital Authority, Hong Kong West Cluster (HKU/HA HKW IRB) (reference no.: UW 20-377). All participants provided their written informed consent prior to participating in this study. Participants were assured of their confidentiality, anonymity, and rights of withdrawal.

\subsection{Data Collection}

Recruitment was started using QR code posters flagged up in the David Trench Rehabilitation Centre in the Queen Mary Hospital, Hospital Authority, Hong Kong since early June 2021. Eligible participants were directed to fill in an online screening questionnaire. The data collection process was obscured due to the third COVID-19 outbreak in July 2021. Hence, we recruited potential participants via an online seminar targeting CGPWD organized in early August 2021. Given the fact that the third wave of COVID-19 outbreak was contained in late September 2021, eventually a follow-up questionnaire was delivered to participants in October 2021 using either telephone interviews or online surveys. The data collection period spanned from June 2021 and October 2021.

\subsection{Outcome Measures}

\subsubsection{Demographics}

Subjects' demographics, including gender, age, marital status, educational level, living circumstances, occupation, and monthly personal income, financial status, personal and family history of mood disorders, relationship with PWD, and caring durations were canvassed. 


\subsubsection{COVID-19 Related Attitudes}

Due to the lack of validated instruments to solicit CGPWD's perceptions towards COVID-19 patients, we thus developed a new eight-item rating scale, jointly designed by a team of psychiatrists who are experts in gerontology in the Department of Psychiatry, University of Hong Kong. This scale scored from 1 (absolutely disagree) to 9 (absolutely agree). Participants were asked to rate statements like "I am so scared of persons with coronavirus" and "People infected with coronavirus are disgusting". Scores ranged from 9 to 72 . Higher scores indicate more negative attitudes towards COVID-19 patients.

\subsubsection{Depressive Symptoms}

Depressive symptoms were examined by a validated self-report 20-item questionnaire, the Chinese Center for Epidemiologic Studies Depression Scale (CES-D) [22,23]. Scores ranged from 0 to 60 , with higher scores indicating more severe depressive symptoms. Participants with a total CES-D score of $\geq 16$ were categorized as having probable depression. The scale showed satisfactory construct validity in the Chinese population [23].

\subsubsection{Perceived Stress}

Perceived stress levels were measured by a 10-item Perceived Stress Scale (PSS-10) [24]. The PSS-10 used a 5-point Likert scale ranging from 0 (never) to 4 (very often), with a higher score indicating a higher stress level. This scale has satisfactory psychometric properties and good reliability [25].

\subsubsection{Anxiety}

The level of anxiety was assessed by a self-rated seven-item Generalized Anxiety Disorder (GAD-7) [26]. GAD-7 uses a 4-point Likert scale ranged from 0 (not at all sure) to 4 (nearly every day). A higher score indicates a higher anxiety level. This scale is proven to have a good reliability and validity in measuring anxiety among the Chinese population [27].

\subsubsection{Caregiver Burden}

Levels of caregiver burden were measured by a self-administrated Zarit Burden Interview-ZBI-22 [28]. Score ranges from 0 to 88, with higher scores indicating higher degree of caregiving burden. The Chinese version of the scale demonstrated good validity and reliability among the CPGWD in Hong Kong [29].

\subsubsection{Degrees of Non-Attachment Traits}

The seven-item Nonattachment Scale (NAS-7) was used to assess participants' levels of wisdom in subjective detachment feelings on internal pressure or experiences. We used the Chinese version of the NAS-7, as it has excellent internal consistency in previous studies [30]. A higher score indicates a higher degree of nonattachment.

\subsubsection{Perceived Social Support}

Perceived social support was measured by the modified Medical Outcomes Study Social Support Survey (mMOS-SS), which comprised eight questions covering emotional and instrumental social support domains. The internal reliability and consistency, construct and discriminant validity were satisfactory [31]. Higher scores indicated more social support [32]. The Chinese version of the mMOS-SS has good psychometric properties [33].

\subsubsection{Perceived Coping Efficacy}

Perceived coping efficacy was assessed by a COVID-19 coping efficacy inventory (2019nCoV-CEI) modified from the SARS Appraisal Inventory (SAI). This scale assessed eight daily life aspects. Participants were asked to rate their level of confidence in dealing with the pandemic influence on a 5-point scale (0: none, 4: very high). The internal consistency of the SAI was satisfactory [34]. 


\subsection{Statistical Analysis}

Statistical analyses were performed using IBM SPSS Statistics Version 26.0 for the Windows platform (SPSS Inc., Chicago, IL, USA). The normality of the data distributions were assessed by QQ plot. Descriptive analysis was used to describe participants' sociodemographic characteristics. Between-group independent samples $t$-tests were used to compare the scores of psychological instruments (CES-D, PSS-10, GAD-7, ZBI-22, NAS-7, mMOS-SS and SAI). Level of significance was set at $p<0.05$ (two-tailed). Participants were categorized into two groups (Depression and non-depression group) using the cut-off point of CESD $\geq 16$. Pearson's correlation analysis and backward multiple regression models were carried out to investigate potential confounding factors on CGPWD's instrumental ratings. Paired samples $t$-tests were used to compare the pre-and-post scores on depressive symptoms, perceived stress, anxiety level, and perceived coping efficacy in different pandemic waves. Missing data was handled by multiple imputation [35].

\section{Results}

A total of 51 CGPWD caregivers participated in this study. Since only completed responses were recorded online, we cannot estimate the overall response rate. Table 1 described the sociodemographic characteristics and baseline instrumental scores of the entire samples across the depression and non-depression group. Participants were predominantly female $(\mathrm{n}=44,86.3 \%)$. Participant ages varied from 25 to 92 years of age. The mean age was 53.54. About half of the sample were single (49.0\%), of which $56.9 \%$ obtained a Bachelor degree or above. Around two-thirds (62.7\%) lived in private housing. A vast majority of participants (88.2\%) either lived alone or living with Persons with Dementia (PWD). Around $40 \%$ (41.2\%) had a monthly personal income of less than HKD 20,000, with 43.1\% having a full-time job. One-fifth $(21.6 \%)$ had a personal or family history of mood disorders. More than three-quarters of respondents (76.4\%) reported that their parents suffered from dementia. Duration of caring for the PWD seemed dispersed in our sample, with most caregivers $(45.1 \%$ ) having less than 10 years of (i.e., 5 to 9 years) of caring experience. More than half of the participants (54.9\%) received community service assistance (e.g., caregiving assistance from non-governmental organisations), while another one-third (33.3\%) sought informal help from friends/ relatives.

Table 1. Demographic characteristics of participants by depression category $(\mathrm{N}=51)$.

\begin{tabular}{|c|c|c|c|c|c|c|c|c|c|}
\hline & & \multicolumn{2}{|c|}{$\begin{array}{c}\text { Entire Sample } \\
\quad(\mathrm{N}=51)\end{array}$} & \multicolumn{2}{|c|}{$\begin{array}{l}\text { Depression } \\
(\mathrm{N}=33)\end{array}$} & \multicolumn{2}{|c|}{$\begin{array}{c}\text { No Depression } \\
(\mathrm{N}=18)\end{array}$} & \multirow{2}{*}{$\chi^{2}(\mathrm{df})$} & \multirow{2}{*}{$p$-Value } \\
\hline & & $\mathbf{N}$ & $\%$ & $\mathbf{N}$ & $\%$ & $\mathbf{N}$ & $\%$ & & \\
\hline \multicolumn{10}{|c|}{ Gender } \\
\hline & Male & 7 & 13.7 & 3 & 16.7 & 4 & 12.1 & \multirow{2}{*}{$\begin{array}{l}0.20 \\
(1)\end{array}$} & \multirow[t]{2}{*}{0.652} \\
\hline & Female & 44 & 86.3 & 15 & 83.3 & 29 & 87.9 & & \\
\hline \multicolumn{10}{|l|}{ Age } \\
\hline & $18-30$ & 2 & 3.9 & 2 & 6.1 & & & \multirow[t]{4}{*}{$\begin{array}{l}4.74 \\
(3)\end{array}$} & \multirow[t]{4}{*}{0.192} \\
\hline & $31-45$ & 9 & 17.6 & 8 & 24.2 & 1 & 5.6 & & \\
\hline & $46-60$ & 26 & 51.0 & 14 & 42.4 & 12 & 66.7 & & \\
\hline & 61 or above & 14 & 27.5 & 9 & 27.3 & 5 & 27.8 & & \\
\hline \multicolumn{10}{|c|}{ Marital status } \\
\hline & Single & 25 & 49.0 & 20 & 60.6 & 5 & 27.8 & \multirow[t]{3}{*}{$\begin{array}{c}5.44 \\
(2)\end{array}$} & \multirow[t]{3}{*}{0.066} \\
\hline & Married/In a relationship & 23 & 45.1 & 12 & 36.4 & 11 & 61.1 & & \\
\hline & Divorced/Separated/Widowed & 3 & 5.9 & 1 & 3.0 & 2 & 11.2 & & \\
\hline
\end{tabular}


Table 1. Cont.

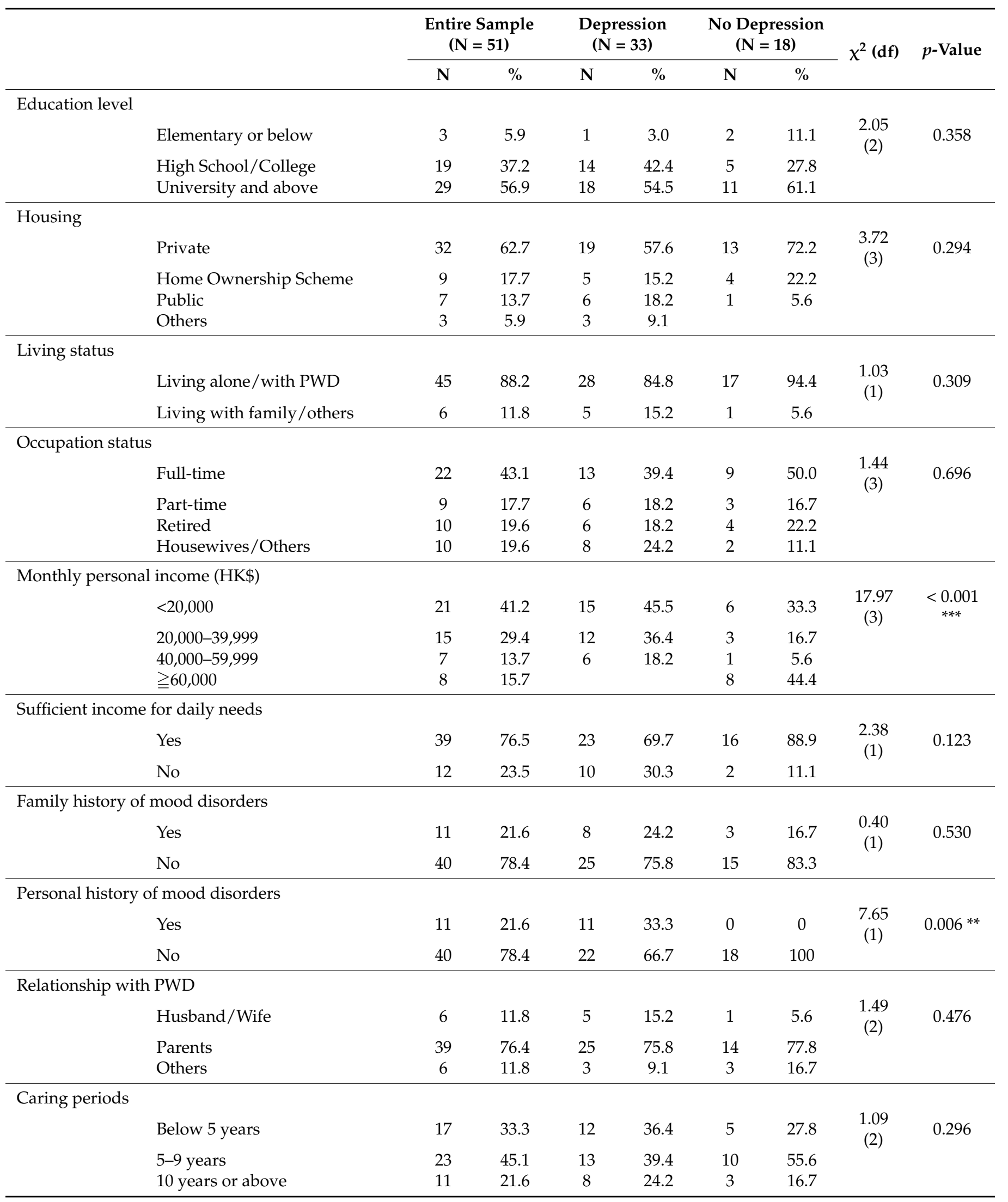


Table 1. Cont.

\begin{tabular}{|c|c|c|c|c|c|c|c|c|}
\hline & \multicolumn{2}{|c|}{$\begin{array}{l}\text { Entire Sample } \\
\quad(\mathrm{N}=51)\end{array}$} & \multicolumn{2}{|c|}{$\begin{array}{l}\text { Depression } \\
(\mathbf{N}=33)\end{array}$} & \multicolumn{2}{|c|}{$\begin{array}{l}\text { No Depression } \\
\quad(\mathrm{N}=18)\end{array}$} & \multirow{2}{*}{$x^{2}(\mathrm{df})$} & \multirow{2}{*}{$p$-Value } \\
\hline & $\mathbf{N}$ & $\%$ & $\mathbf{N}$ & $\%$ & $\mathbf{N}$ & $\%$ & & \\
\hline \multicolumn{9}{|l|}{ Community aids (e.g., hiring helpers) } \\
\hline Yes & 28 & 54.9 & 16 & 48.5 & 12 & 66.7 & \multirow{2}{*}{$\begin{array}{l}0.17 \\
(1)\end{array}$} & \multirow[t]{2}{*}{0.678} \\
\hline No & 23 & 45.1 & 17 & 51.5 & 6 & 33.3 & & \\
\hline \multicolumn{9}{|l|}{ Informal help (e.g., friends) } \\
\hline Yes & 17 & 33.3 & 11 & 33.3 & 6 & 33.3 & $0(1)$ & 1 \\
\hline No & 34 & 66.7 & 22 & 66.7 & 12 & 66.7 & & \\
\hline Baseline Assessments & $\mathbf{M}$ & SD & $\mathbf{M}$ & SD & M & SD & $t$ & $p$-Value \\
\hline $\begin{array}{l}\text { Center for Epidemiologic Studies Depression Scale } \\
\text { (CES-D) }\end{array}$ & 19.76 & 11.69 & 26.03 & 9.54 & 8.28 & 3.80 & 7.55 & $<0.001$ \\
\hline Perceived Stress Scale-10 (PSS-10) & 21.96 & 4.76 & 23.00 & 4.68 & 20.06 & 4.41 & 2.19 & 0.033 * \\
\hline Generalized Anxiety Disorder (GAD-7) & 6.86 & 5.21 & 9.21 & 4.08 & 2.56 & 4.26 & 5.49 & $\underset{* * *}{<0.001}$ \\
\hline Zarit Burden Scale (ZBI-22) & 40.78 & 17.05 & 47.94 & 12.90 & 27.67 & 16.13 & 4.91 & $\underset{* * *}{<0.001}$ \\
\hline Non-attachment Scale (NAS-7) & 30.33 & 5.87 & 28.27 & 5.54 & 34.11 & 4.50 & -3.83 & $\underset{* * *}{<0.001}$ \\
\hline $\begin{array}{l}\text { modified Medical Outcomes Study Social Support } \\
\text { Survey (mMOS-SS) }\end{array}$ & 21.75 & 7.06 & 21.85 & 6.29 & 21.56 & 8.48 & 0.14 & 0.889 \\
\hline Instrumental & 10.12 & 4.17 & 10.24 & 3.41 & 9.89 & 5.40 & 0.29 & 0.776 \\
\hline Emotional & 11.63 & 3.72 & 11.61 & 3.66 & 11.67 & 3.94 & -0.06 & 0.956 \\
\hline Perceived Coping Efficacy-Impact & 1.83 & 0.73 & 2.03 & 0.66 & 1.48 & 0.74 & 2.72 & $0.009 * *$ \\
\hline Perceived Coping Efficacy-Confidence & 2.40 & 0.58 & 2.32 & 0.53 & 2.55 & 0.66 & -1.33 & 0.188 \\
\hline
\end{tabular}

Note. ${ }^{*} p<0.05 ; * * p<0.01 ; * * * p<0.001 \mathrm{~N}=$ total number of participants; $\mathrm{M}=$ mean; $\mathrm{SD}=$ standard deviation; PWD = persons with Dementia. Chi-squares $\left(\chi^{2}\right) / t$-tests $(t)$ comparing depression/non-depression groups. Depression group is defined by a total CES-D cut-off score of $\geq 16$.

Regarding the point prevalence of depressive symptoms for CGPWD, participants' mean total CES-D score was $19.76(S D=11.69)$, suggesting the likelihood of having moderate depression. Nearly two-third of respondents $(n=33,64.7 \%)$ were identified with high risks of probable depression (total CES-D score $\geq 16$ ), and there was a statistically significant difference in mean score between the depression and the non-depression group $(t=7.55, p<0.001)$. Results from independent samples $t$-tests also showed significant differences on perceived stress, anxiety, caregiving burden, non-attachment, and perceived pandemic impact between depression and non-depression groups (all $p<0.05)$. Chi-square analyses revealed statistically significant correlations between monthly income $(p<0.001)$ and personal history of mood disorders $(p=0.006)$.

Table 2 showed the results of Pearson correlational matrix across the psychometric variables. Our findings revealed that caregivers' attitudes on COVID-19 was significantly related to depressive symptoms, perceived stress, anxiety, caregiving burden, and confidence in pandemic coping (all $p<0.05$ ). CGPWD who perceived the pandemic as more severe were associated with higher levels of depressive symptoms, perceived stress, anxiety, and caregiving burden. In order to identify the parsimonious combination of variables contributing towards the psychological distress, backward multiple regression analyses were conducted by using the total scores of CES-D, PSS-10 and GAD-7 as dependent variables. The ratings on ZBI-22, NAS-7, mMOS-SS, COVID-19 attitudes, and perceived impact were entered in the regression model as predictors. The regression analyses are summarized in Table 3. 
Table 2. Pearson correlational matrix regarding CGPWD's attitude on COVID-19 and their psychosocial wellbeing $(\mathrm{N}=51)$.

\begin{tabular}{|c|c|c|c|c|c|c|c|c|c|}
\hline Measures & (1) & (2) & (3) & (4) & (5) & (6) & (7) & (8) & (9) \\
\hline $\begin{array}{l}\text { (1) Attitudes on } \\
\text { COVID-19 }\end{array}$ & 1.000 & & & & & & & & \\
\hline (2) Depression & $0.481^{* * *}$ & 1.000 & & & & & & & \\
\hline (3) Perceived Stress & $0.385 * *$ & $0.574^{* * *}$ & 1.000 & & & & & & \\
\hline (4) Anxiety & $0.376^{* *}$ & $0.780 * * *$ & $0.600^{* * *}$ & 1.000 & & & & & \\
\hline (5) Caregiving burden & $0.444^{* *}$ & $0.708^{* * *}$ & $0.592 * * *$ & $0.742^{* * *}$ & 1.000 & & & & \\
\hline (6) Non-attachment & -0.188 & $-0.429 * *$ & -0.059 & $-0.326^{*}$ & $-0.284 *$ & 1.000 & & & \\
\hline (7) Social support & -0.019 & -0.017 & $0.314 *$ & 0.176 & 0.250 & 0.148 & 1.000 & & \\
\hline (8) Perceived impact & 0.121 & $0.357^{*}$ & $0.458^{* *}$ & $0.445^{* *}$ & $0.485^{* * *}$ & -0.097 & 0.251 & 1.000 & \\
\hline (9) Perceived confidence & $-0.291 *$ & -0.161 & -0.120 & -0.171 & -0.160 & 0.276 & 0.222 & $-0.329 *$ & 1.000 \\
\hline
\end{tabular}

Note. ${ }^{*} p<0.05,{ }^{* *} p<0.01,{ }^{* * *} p<0.001$.

Table 3. Backward multiple regressions analyses identifying significant correlates of Depression, Stress and Anxiety among CGPWD $(\mathrm{N}=51)$.

\begin{tabular}{|c|c|c|c|c|c|c|c|c|c|}
\hline \multirow{2}{*}{ Variable } & \multicolumn{3}{|c|}{ Depression } & \multicolumn{3}{|c|}{ Stress } & \multicolumn{3}{|c|}{ Anxiety } \\
\hline & $\beta(95 \% \mathrm{CI})$ & $p$ & $R^{2}$ & $\beta(95 \% \mathrm{CI})$ & $p$ & $R^{2}$ & $\beta(95 \% \mathrm{CI})$ & $p$ & $R^{2}$ \\
\hline Initial Model & & & 0.607 & & & 0.449 & & & 0.579 \\
\hline $\begin{array}{l}\text { Caregiving } \\
\text { burden }\end{array}$ & $\begin{array}{c}0.571 \\
(0.217,0.565)\end{array}$ & $<0.001^{* * *}$ & & $\begin{array}{c}0.379 \\
(0.022,0.190)\end{array}$ & $0.015^{*}$ & & $\begin{array}{c}0.614 \\
(0.107,0.268)\end{array}$ & $<0.001^{* * *}$ & \\
\hline $\begin{array}{c}\text { Non- } \\
\text { attachment }\end{array}$ & $\begin{array}{c}-0.205 \\
(-0.811,-0.006)\end{array}$ & $0.047 *$ & & $\begin{array}{c}0.086 \\
(-0.124,0.264)\end{array}$ & 0.474 & & $\begin{array}{c}-0.129 \\
(-0.300,0.071)\end{array}$ & 0.220 & \\
\hline $\begin{array}{l}\text { Social } \\
\text { support }\end{array}$ & $\begin{array}{c}-0.144 \\
(-0.156,0.027)\end{array}$ & 0.160 & & $\begin{array}{c}0.156 \\
(-0.016,0.072)\end{array}$ & 0.200 & & $\begin{array}{c}0.012 \\
(-0.040,0.044)\end{array}$ & 0.907 & \\
\hline $\begin{array}{l}\text { Attitudes on } \\
\text { COVID-19 }\end{array}$ & $\begin{array}{c}0.177 \\
(-0.047,0.500)\end{array}$ & 0.102 & & $\begin{array}{c}0.209 \\
(-0.023,0.241)\end{array}$ & 0.103 & & $\begin{array}{c}0.065 \\
(-0.089,0.163)\end{array}$ & 0.559 & \\
\hline $\begin{array}{l}\text { Perceived } \\
\text { impact }\end{array}$ & $\begin{array}{c}0.075 \\
(-2.297,4.709)\end{array}$ & 0.492 & & $\begin{array}{c}0.219 \\
(-0.265,3.112)\end{array}$ & 0.096 & & $\begin{array}{c}0.123 \\
(-0.735,2.495)\end{array}$ & 0.278 & \\
\hline Final Model & & & 0.587 & & & 0.415 & & & 0.551 \\
\hline $\begin{array}{l}\text { Caregiving } \\
\text { burden }\end{array}$ & $\begin{array}{c}0.557 \\
(0.234,0.530)\end{array}$ & $<0.001^{* * *}$ & & $\begin{array}{c}2.760 \\
(0.030,0.190)\end{array}$ & $0.008^{* *}$ & & $\begin{array}{c}0.742 \\
(0.168,0.285)\end{array}$ & $<0.001^{* * *}$ & \\
\hline $\begin{array}{c}\text { Non- } \\
\text { attachment }\end{array}$ & $\begin{array}{c}-0.236 \\
(-0.861,-0.076)\end{array}$ & $0.020 *$ & & - & - & & - & - & \\
\hline $\begin{array}{l}\text { Attitudes on } \\
\text { COVID-19 }\end{array}$ & $\begin{array}{c}0.189 \\
(-0.028,0.513)\end{array}$ & 0.078 & & $\begin{array}{c}1.440 \\
(-0.037,0.226)\end{array}$ & 0.157 & & - & - & \\
\hline $\begin{array}{l}\text { Perceived } \\
\text { impact }\end{array}$ & - & - & & $\begin{array}{c}1.915 \\
(-0.081,3.287)\end{array}$ & 0.062 & & - & - & \\
\hline
\end{tabular}

Note: ${ }^{*} p<0.05,{ }^{* *} p<0.01,{ }^{* * *} p<0.001, \beta=$ regression coefficient; $R^{2}=\mathrm{R}$ squared; $\mathrm{CI}=$ confidence interval.

Overall, the final models regarding depression, stress, and anxiety account for $58.7 \%$, $41.5 \%$ and $55.1 \%$ of variance, respectively. The final model had identified caregiving burden, non-attachment, and attitudes on COVID-19, with caregiving burden and non-attachment as significant predictors of depression $(F(3,47)=22.24, p<0.001)$. The stress model with the most parsimonious predictor variables included caregiving burden, attitudes on COVID19 , and perceived impact, with caregiving burden identified as significant contributor $(F(3,47)=11.11, p<0.001)$. For anxiety, caregiving burden was the only significant predictor $(F(1,49)=60.14, p<0.001)$.

For the follow-up survey, 43 responses were obtained. Table 4 presented the results of paired sample $t$-tests on depression, stress, anxiety, and perceived coping efficacy. Participants demonstrated significantly higher depressive symptoms as evaluated by CES-D after the third wave outbreak $(t=2.25, p=0.03)$. An increase in perceived stress (mean difference $=0.42$ ) and anxiety (mean difference $=0.37$ ) was also noted despite the fact that these figures were statistically insignificant. The trend of having lessening concerns in epidemic impact was observed (from 1.83 to 1.69), yet the overall confidence in coping efficacy decreased (from 2.41 to 2.28 ). 
Table 4. Paired samples $t$-tests comparing baseline and follow-up assessment scores $(\mathrm{N}=43)$.

\begin{tabular}{|c|c|c|c|c|c|c|}
\hline & \multicolumn{2}{|c|}{ Baseline } & \multicolumn{2}{|c|}{ Follow-Up } & \multirow{2}{*}{$t$} & \multirow{2}{*}{$p$-Value } \\
\hline & $\mathbf{M}$ & SD & $\mathbf{M}$ & SD & & \\
\hline $\begin{array}{l}\text { Center for Epidemiologic } \\
\text { Studies Depression Scale } \\
\text { (CES-D) }\end{array}$ & 19.40 & 12.12 & 22.40 & 11.10 & 2.25 & 0.030 * \\
\hline $\begin{array}{l}\text { Perceived Stress Scale-10 } \\
\text { (PSS-10) }\end{array}$ & 22.02 & 5.11 & 22.44 & 3.72 & 0.59 & 0.558 \\
\hline $\begin{array}{l}\text { Generalized Anxiety Disorder } \\
\text { (GAD-7) }\end{array}$ & 6.79 & 5.24 & 7.16 & 4.39 & 0.53 & 0.598 \\
\hline $\begin{array}{l}\text { Perceived Coping } \\
\text { Efficacy-Impact }\end{array}$ & 1.83 & 0.77 & 1.69 & 0.73 & -1.31 & 0.198 \\
\hline $\begin{array}{l}\text { Perceived Coping } \\
\text { Efficacy_Efficacy }\end{array}$ & 2.41 & 0.61 & 2.28 & 0.71 & -1.27 & 0.211 \\
\hline
\end{tabular}

Note. ${ }^{*} p<0.05 . \mathrm{M}=$ mean; $\mathrm{SD}=$ standard deviation. $t$-tests $(t)$ comparing baseline and follow-up data.

\section{Discussion}

It is evident that our CGPWD manifested moderate depressive symptoms in caring the PWD during the second and third wave amid COVID-19 outbreak in Hong Kong. The prevalence rate of probable depression among the 51 dementia caregivers was $64.7 \%$ in this study, which is even higher than another cross-sectional study conducted in the general population in Hong Kong in an earlier COVID-19 outbreak period in Hong Kong, which revealed that $46.5 \%(n=11,072)$ of participants suffered from probable depression (using a cut off PHQ-9 score $\geq 10$ ) [8]. The mean total of CES-D and ZBI-22 scores in our study are also higher than the scores that emanated from an American study beyond the pandemic period (CES-D total score: 19.76 vs 16.09; ZBI-22 total score: 40.78 vs 38.61) [36], suggesting a remarkable deterioration of mental well-being precipitated by the COVID-19 outbreak. An increase in depressive symptoms among CGPWD is also noted in the follow-up survey, which is not anticipated considering the cumulation of the third coronavirus outbreak. In addition, the results consolidate the verdict on exacerbated behavioural and psychological symptoms during COVID-19 quarantine circumstance despite contextual differences [20].

CGPWD with probable depression in this study also report high levels of anxiety, perceived stress, and caregiving burden, along with a more pessimistic attribute on nonattachment idiosyncrasy impacted by the coronavirus. Results obtained from this study further affirm that the caregiving burden and anxiety of the CGPWD should not be underestimated, as our results echoed another Chinese study conducted on family caregivers of schizophrenia individuals [35] which revealed the mean score of 48 using the ZBI-22. This score was very close to our ZBI-22 score among the depression group $(M=47.9)$. The mean GAD-7 score of Yu's study was 9.3 $(S D=6.6)$, which is also analogous to our GAD-7 score $(M=9.2, S D=4.1)$ despite the disparity in the caregiving nature [37].

The high prevalence of depressive symptoms reported from CGPWD in this study delivered a significant message to policymakers and healthcare providers. The emergence of COVID-19 has a high resemblance to the outbreak of the 2003 severe acute respiratory syndrome (SARS) in Hong Kong, which claimed 299 lives [38]. It is unsurprising that the general population in Hong Kong strictly complied with the stringent infection control measures, especially those who had experienced the SARS outbreak, for instance, with the wearing of face masks and frequent handwashing and compulsory quarantines etc. These imminent infection control measures have inevitably re-triggered their past fear towards the 2003 SARS outbreak that subsequently intensified Hong Kong citizens' psychological distress and anxiety [6]. The rapid transmission of this novel virus has triggered intense fear, stress, anxiety and depression, particularly if individuals perceive themselves as more susceptible to COVID-19 infection than others [39]. Negative news portrayal and insufficient knowledge on the transmission route and precautionary measures towards COVID-19 may trigger further uncertainty and negative psychological symptoms [40]. The 
relatively high level of depressive symptom score implies that CGPWD with high caregiving burden and less non-attachment awareness have increased likelihood of reporting more severe depressive symptoms. The lack of non-attachment feeling on internal pressure and adversities by caregivers could intensify their sentiment on the impact of COVID-19 and caregiving burden in manipulating potential psychological distress. The stringent quarantine measures might lead to increased caregiving duration, resulting in deprived personal private time for CGPWD. This prolonged caregiving burden may increase perceived powerlessness and physical and mental exhaustion that eventually jeopardize CGPWD's mental wellbeing [41].

Furthermore, participants with probable depression were significantly and inversely associated with monthly income and personal history of mood disorders. Higher depressive symptoms are predominantly present in caregivers with lower monthly income. This phenomenon may partially explain by the socioeconomic downturn brought by COVID-19 in Hong Kong. It is noteworthy that most participants with probable depression did not have a psychiatric history of mood disorders. We speculate that these CGPWD may have poor awareness and mental health literacy of their increasing severity of their psychiatric symptoms and thus, they did not seek professional help in a timely fashion. Poor mental health literacy might lead to undesirable tragedy with possible suicidal ideations or harmful actions to the PWD [42]. Our results indicate that contingent mental health services and intervention including telemedicine and digital online psychiatric consultation [43] by mental health experts should be urgently established (e.g., Zoom consultation and emergency community outreach) to assist the CGPWD to cope with insurmountable psychological pressure amid the COVID-19 pandemic [44]. Delivery of digital/online mental health information or services regarding professional mental health seeking methods, management of crisis interventions, and an emergency 24-h helpline directory for at-risk individuals, should be extensively disseminated in online social media via joint effort by the Department of Health, the Centre for Health Protection, and the Hospital Authority in Hong Kong. These health authorities should form a collaborative alliance to formulate effective, tailor-made interventions specifically for improving CGPWD's mental health literacy and to enhance professional help-seeking behaviour during the pandemic era.

\section{Limitations}

There are a few limitations that we must acknowledge in this study. Since face-toface interviews were all suspended during the initial COVID-19 outbreak, we could only rely on online surveys which is not uncommon to generate relatively low enrolment and response rate. Second, the use of QR code enrolment in our online survey may filter out some potential participants, for example, CGPWD with severe depression, and those with technical phobia. Third, prolonged data collection periods limit the accuracy and reliability of the findings given the everchanging coronavirus upheavals in Hong Kong. Fourth, the study did not have any pre-pandemic data on the CGPWD population which may serve as a comparison cohort for this study. Hence, results emerged from a small sample size in this study may not be generalized to other countries. Fifth, due to cross-sectional design, causality between CGPWD and psychological impact cannot be inferred. Despite all these limitations, our findings highlight an important message that CGPWD is also an at-risk group which seems to be under-investigated in the existing literature. More research in this subpopulation is warranted. Future replication of further studies using longitudinal or qualitative design with larger sample size using representative samples is recommended. Despite its relatively small sample size, our study findings have shed insight on mental health professionals and public health policymakers that CGPWD caregivers with probable depression tend to perceive higher anxiety, stress, and caregiving burden alongside with a more pessimistic perspective on COVID-19. 


\section{Conclusions}

It is evident that CGPWD have a high prevalence of depressive symptoms as a result of the COVID-19 outbreak in Hong Kong. It is highly likely that participants' level of depression may further spiral upwards if there is still no timely effective mental health intervention in place in this pandemic era. Apart from the caregiving burden, CGPWD with non-attachment are also more prone to reporting more depressive symptoms. The high point prevalence of probable depression among CGPWD sends a strong message that there is a pressing need of provision of contingent mental health interventions/practical assistance/financial subsidy from allied mental health professionals and social welfare departments in order to restore CGPWD's mental wellbeing so as to reduce the increasing risk of psychiatric morbidity and global disease burden brought by this COVID-19 pandemic.

Author Contributions: Conceptualization, C.P.-W.C. and T.K.-H.F.; Methodology, C.P.-W.C. and T.K.-H.F.; Validation, C.P.-W.C., W.-C.C. and T.C. Formal Analysis, T.K.-H.F.; Investigation, T.K.-H.F.; Resources, C.P.-W.C. and W.-C.C.; Data Curation, C.P.-W.C.; Writing-Original Draft Preparation, T.K.-H.F.; Writing-Review \& Editing, C.P.-W.C., W.-C.C. and T.C.; Visualization, T.K.-H.F.; Supervision, W.-C.C.; Project Administration, C.P.-W.C. All authors have read and agreed to the published version of the manuscript.

Funding: This research received no external funding.

Institutional Review Board Statement: The study was conducted according to the guidelines of the Declaration of Helsinki, and approved by the Institutional Review Board (or Ethics Committee) of The University of Hong Kong/Hospital Authority, Hong Kong West Cluster (HKU/HA HKW IRB) (reference no.: UW 20-377, 20 May 2020).

Informed Consent Statement: Informed consent was obtained from all subjects involved in the study.

Data Availability Statement: Anonymous data is available on request.

Acknowledgments: We would like to thank those participants who have participated in this study.

Conflicts of Interest: The authors declare no conflict of interest.

\section{References}

1. Hong Kong Government. Coronavirus Disease (COVID-19) in HK. Available online: https://www.coronavirus.gov.hk/eng/ index.html (accessed on 16 December 2021).

2. World Health Organisation. Coronavirus Disease (COVID-19) Pandemic. Available online: https://www.who.int/emergencies/ diseases / novel-coronavirus-2019?gclid=Cj0KCQjwvO2IBhCzA-IsALw3ASo5Ud0LX4RcGQ2hJILmbo5UfBlnP2DKtMLPk-BRDRSCyvvjkihFj0aAvvxEALw_wcB (accessed on 19 December 2021).

3. Xiang, Y.-T.; Yang, Y.; Li, W.; Zhang, L.; Zhang, Q.; Cheung, T.; Ng, C.H. Timely mental health care for the 2019 novel coronavirus outbreak is urgently needed. Lancet Psychiatry 2020, 7, 228-229. [CrossRef]

4. Cullen, W.; Gulati, G.; Kelly, B.D. Mental health in the COVID-19 pandemic. QJM Int. J. Med. 2020, 113, 311-312. [CrossRef]

5. Hyland, P.; Shevlin, M.; McBride, O.; Murphy, J.; Karatzias, T.; Bentall, R.P.; Martinez, A.; Vallières, F. Anxiety and depression in the Republic of Ireland during the COVID-19 pandemic. Acta Psychiatr. Scand. 2020, 142, 249-256. [CrossRef] [PubMed]

6. Cheung, T.; Fong, K.H.T.; Bressington, D. COVID-19 under the cloud of SARS: Mental health nursing during the pandemic in Hong Kong. J. Psychiatr. Ment. Health Nurs. 2020, 28, 115-117. [CrossRef] [PubMed]

7. Chinese University of Hong Kong. CU Medicine Announces the Community Response Study Results during the Early Phase of the COVID-19 Outbreak in Hong Kong. Available online: https://www.cpr.cuhk.edu.hk/en/press_detail.php?id=3234\&t= cu-medicine-announces-the-community-response-study-results-during-the-early-phase-of-the-COVID-19-outbreak-in-hongkong (accessed on 16 April 2020).

8. $\quad$ Bressington, D.T.; Cheung, T.C.C.; Lam, S.C.; Suen, L.K.P.; Fong, T.K.H.; Ho, H.S.W.; Xiang, Y.-T. Association between depression, health beliefs, and face mask use during the COVID-19 pandemic. Front. Psychiatry 2020, 11, 571179. [CrossRef]

9. Wang, D.; Hu, B.; Hu, C.; Zhu, F.; Liu, X.; Zhang, J.; Wang, B.; Xiang, H.; Cheng, Z.; Xiong, Y.; et al. Clinical characteristics of 138 hospitalized patients with 2019 novel coronavirus-infected pneumonia in Wuhan, China. JAMA 2020, 323, 1061-1069. [CrossRef]

10. Liu, K.; Fang, Y.-Y.; Deng, Y.; Liu, W.; Wang, M.-F.; Ma, J.-P.; Xiao, W.; Wang, Y.-N.; Zhong, M.-H.; Li, C.-H.; et al. Clinical characteristics of novel coronavirus cases in tertiary hospitals in Hubei Province. Chin. Med. J. 2020, 133, 1025-1031. [CrossRef] [PubMed]

11. Centre for Health Protection. Frequently Asked Questions on Coronavirus Disease 2019 (COVID-19). Available online: https: //www.chp.gov.hk/en/features/102624.html\#FAQ9 (accessed on 20 April 2020). 
12. Hospital Authority. Dementia. Available online: https://www21.ha.org.hk/smartpatient/SPW/en-US/Disease-Information/ Disease/?guid=0ff3b12b-b3c0-4fa9-9bac-6bcf9dc501ba (accessed on 21 March 2021).

13. Mahoney, R.; Regan, C.; Katona, C.; Livingston, G. Anxiety and depression in family caregivers of people with Alzheimer disease: The LASER-AD study. Am. J. Geriatr. Psychiatry 2005, 13, 795-801. [CrossRef]

14. Lee, J.; Sohn, B.K.; Lee, H.; Seong, S.; Park, S.; Lee, J.Y. Impact of behavioral symptoms in dementia patients on depression in daughter and daughter-in-law caregivers. J. Women's Health 2017, 26, 36-43. [CrossRef]

15. Cheung, K.S.-L.; Lau, B.H.-P.; Wong, P.W.-C.; Leung, A.Y.-M.; Lou, V.W.Q.; Chan, G.M.-Y.; Schulz, R. Multicomponent intervention on enhancing dementia caregiver well-being and reducing behavioral problems among Hong Kong Chinese: A translational study based on REACH II. Int. J. Geriatr. Psychiatry 2015, 30, 460-469. [CrossRef]

16. Altieri, M.; Santangelo, G. The psychological impact of COVID-19 pandemic and lockdown on caregivers of people with dementia. Am. J. Geriatr. Psychiatry 2021, 29, 27-34. [CrossRef] [PubMed]

17. Igarashi, A.; Fukuda, A.; Teng, L.; Ma, F.; Dorey, J.; Onishi, Y. Family caregiving in dementia and its impact on quality of life and economic burden in Japan-Web-based survey. Value Health 2017, 20, A403. [CrossRef]

18. Lee, J.J.; Tsang, W.N.; Yang, S.C.; Kwok, J.Y.Y.; Lou, V.W.; Lau, K.K. Qualitative study of chinese stroke caregivers' caregiving experience during the COVID-19 pandemic. Stroke 2021, 52, 1407-1414. [CrossRef] [PubMed]

19. Hong Kong Government, H.K.S.A.R. New Regulations to Fight COVID-19. Available online: https://www.news.gov.hk/eng/20 20/03/20200327/20200327_202339_445.html (accessed on 15 April 2020).

20. Son, J.; Erno, A.; Shea, D.G.; Femia, E.E.; Zarit, S.H.; Stephens, M.A.P. The caregiver stress process and health outcomes. J. Aging Health 2007, 19, 871-887. [CrossRef] [PubMed]

21. Cagnin, A.; Di Lorenzo, R.; Marra, C.; Bonanni, L.; Cupidi, C.; Laganà, V.; Rubino, E.; Vacca, A.; Provero, P.; Isella, V.; et al Behavioral and psychological effects of coronavirus disease-19 quarantine in patients with dementia. Front. Psychiatry 2020, 11, 916. [CrossRef]

22. Radloff, L.S. The CES-D scale: A self-report depression scale for research in the general population. Appl. Psychol. Meas. 1977, 1, 385-401. [CrossRef]

23. Cheung, C.-K.; Bagley, C. Validating an American scale in Hong Kong: The center for epidemiological studies depression scale (CES-D). J. Psychol. 1998, 132, 169-186. [CrossRef]

24. Cohen, S.; Kamarck, T.; Mermelstein, R. A global measure of perceived stress. J. Health Soc. Behav. 1983, 24, 385-396. [CrossRef]

25. Leung, D.Y.; Lam, T.H.; Chan, S.S. Three versions of perceived stress scale: Validation in a sample of Chinese cardiac patients who smoke. BMC Public Health 2010, 10, 513-517. [CrossRef] [PubMed]

26. Spitzer, R.L.; Kroenke, K.; Williams, J.B.; Löwe, B. A brief measure for assessing generalized anxiety disorder: The GAD-7. Arch Intern. Med. 2006, 166, 1092-1097. [CrossRef]

27. Tong, X.; An, D.; McGonigal, A.; Park, S.-P.; Zhou, D. Validation of the generalized anxiety disorder-7 (GAD-7) among Chinese people with epilepsy. Epilepsy Res. 2016, 120, 31-36. [CrossRef] [PubMed]

28. Zarit, S.H.; Reever, K.E.; Bach-Peterson, J. Relatives of the impaired elderly: Correlates of feelings of burden. Gerontologist 1980, 20, 649-655. [CrossRef] [PubMed]

29. Chan, T.S.-F.; Lam, L.C.-W.; Chiu, H.F.-K. Validation of the Chinese version of the Zarit burden interview. Hong Kong J. Psychiatry 2005, 15, 9-14.

30. Chio, F.H.N.; Lai, M.H.C.; Mak, W.W.S. Development of the nonattachment scale-short form (NAS-SF) using item response theory. Mindfulness 2018, 9, 1299-1308. [CrossRef]

31. Moser, A.; Stuck, A.E.; Silliman, R.A.; Ganz, P.A.; Clough-Gorr, K.M. The eight-item modified medical outcomes study social support survey: Psychometric evaluation showed excellent performance. J. Clin. Epidemiol. 2012, 65, 1107-1116. [CrossRef] [PubMed]

32. Sherbourne, C.D.; Stewart, A.L. The MOS social support survey. Soc. Sci. Med. 1991, 32, 705-714. [CrossRef]

33. Yu, D.S.; Lee, T.F.D.; Woo, J. Psychometric testing of the Chinese version of the medical outcomes study social support survey (MOS-SSS-C). Res. Nurs. Health 2004, 27, 135-143. [CrossRef]

34. Cheng, S.K.W.; Chong, G.H.C.; Chang, S.S.Y.; Wong, C.W.; Wong, C.S.Y.; Wong, M.T.P.; Wong, K.C. Adjustment to severe acute respiratory syndrome (SARS): Roles of appraisal and post-traumatic growth. Psychol. Health 2006, 21, 301-317. [CrossRef]

35. Boussat, B.; François, O.; Viotti, J.; Seigneurin, A.; Giai, J.; François, P.; Labarère, J. Managing missing data in the hospital survey on patient safety culture: A simulation study. J. Patient Saf. 2019, 17, E98-E106. [CrossRef]

36. Pillemer, S.; Davis, J.; Tremont, G. Gender effects on components of burden and depression among dementia caregivers. Aging Ment. Health 2018, 22, 1162-1167. [CrossRef]

37. Yu, Y.; Liu, Z.-W.; Zhou, W.; Zhao, M.; Qiu, D.; Li, Y.-L.; Xiao, S.-Y. Cutoff of the Zarit Burden Interview in predicting depression and anxiety. Qual. Life Res. 2019, 28, 2525-2533. [CrossRef] [PubMed]

38. World Health Organization. Summary Table of SARS Cases by Country, 1 November 2002-7 August 2003. Available online: http:/ / www.who.int/csr/sars / country / country2003_08_15.pdf (accessed on 18 June 2020).

39. Lin, Y.; Hu, Z.; Alias, H.; Wong, L.P. Knowledge, attitudes, impact, and anxiety regarding COVID-19 infection among the public in China. Front. Public Health 2020, 8, 236. [CrossRef]

40. Planchuelo-Gómez, Á.; Odriozola-González, P.; Irurtia, M.J.; De Luis-García, R. Longitudinal evaluation of the psychological impact of the COVID-19 crisis in Spain. J. Affect. Disord. 2020, 277, 842-849. [CrossRef] [PubMed] 
41. Lethin, C.; Renom-Guiteras, A.; Zwakhalen, S.; Soto-Martin, M.; Saks, K.; Zabalegui, A.; Challis, D.J.; Nilsson, C.; Karlsson, S. Psychological well-being over time among informal caregivers caring for persons with dementia living at home. Aging Ment. Health 2017, 21, 1138-1146. [CrossRef]

42. Tsang, C.L.E. Hong Kong Couple Found Dead in Suspected Murder-Suicide. Available online: https://www.scmp.com/news/ hong-kong/law-crime/article/2071015/hong-kong-couple-found-dead-suspected-murder-suicide (accessed on 2 December 2020).

43. Liu, S.; Yang, L.; Zhang, C.; Xiang, Y.-T.; Liu, Z.; Hu, S.; Zhang, B. Online mental health services in China during the COVID-19 outbreak. Lancet Psychiatry 2020, 7, e17-e18. [CrossRef]

44. Li, W.; Yang, Y.; Liu, Z.-H.; Zhao, Y.-J.; Zhang, Q.; Zhang, L.; Cheung, T.; Xiang, Y.-T. Progression of mental health services during the COVID-19 outbreak in China. Int. J. Biol. Sci. 2020, 16, 1732-1738. [CrossRef] 